\title{
Research on the Risk of O2O Fresh Agricultural Supply Chain
}

\author{
Xiangxiang Wang ${ }^{\mathrm{a}}$, Li Zhang ${ }^{\mathrm{b}}$, Jiaxin $\mathrm{Li}^{\mathrm{c}}$ \\ Tianjin University of Science\&Technology,Tianjin 30022,China \\ a18322695586@163.com, bjannyzl@163.com, cjancy94@sina.com
}

Keywords: $\mathrm{O} 2 \mathrm{O}$ model, supply chain risk, fresh agricultural, motion optimization.

\begin{abstract}
With the rapid development of the Internet, the supply chain of fresh agricultural products under the $\mathrm{O} 2 \mathrm{O}$ model is booming. This paper analyzes the various types of risks that exist in each link of the entire supply chain, applies a multistage fuzzy comprehensive evaluation method, adopts a combination of qualitative and quantitative analysis of each risk in the supply chain, and analyzes the results. The paper proposes a solution to the risks of fresh agricultural products supply chain under the O2O model.
\end{abstract}

\section{Introduction}

The $\mathrm{O} 2 \mathrm{O}$ of fresh agricultural is the new business model that best suits the consumer's small-scale and personalized business. However, because of the high cost of cold chain logistics and the special nature of fresh agricultural products, the $\mathrm{B} 2 \mathrm{C}$ and $\mathrm{C} 2 \mathrm{C}$ models tend to mature. The drawbacks begin to appear and the customer experience cannot be fully satisfied, while the emergence of the fresh agricultural product supply chain under the $\mathrm{O} 2 \mathrm{O}$ model has been resolved. The $\mathrm{O} 2 \mathrm{O}$ model is a business model in which users are provided with business information through the Internet, consumers subscribe to goods or services online, and then go online to enjoy services [1]. Domestic literature [2][3][4][5] is less researched on quantitative analysis of quantitative analysis of risk assessment and avoidance of fresh agricultural product supply chain under the O2O model.

\section{The Risk Identification and Analysis}

\subsection{The Risk Identification of Fresh Agricultural Supply Chain in O2O Model.}

The source of risk for fresh produce supply chain is mainly include two aspects. First, the uncertainty external environment of the supply chain: external environmental risk. Second, the risk existing between the internal of the supply chain: cooperation risk, planned production risk, logistics risk, operation risk. Supply chain risk identification as shown in Figure 1.

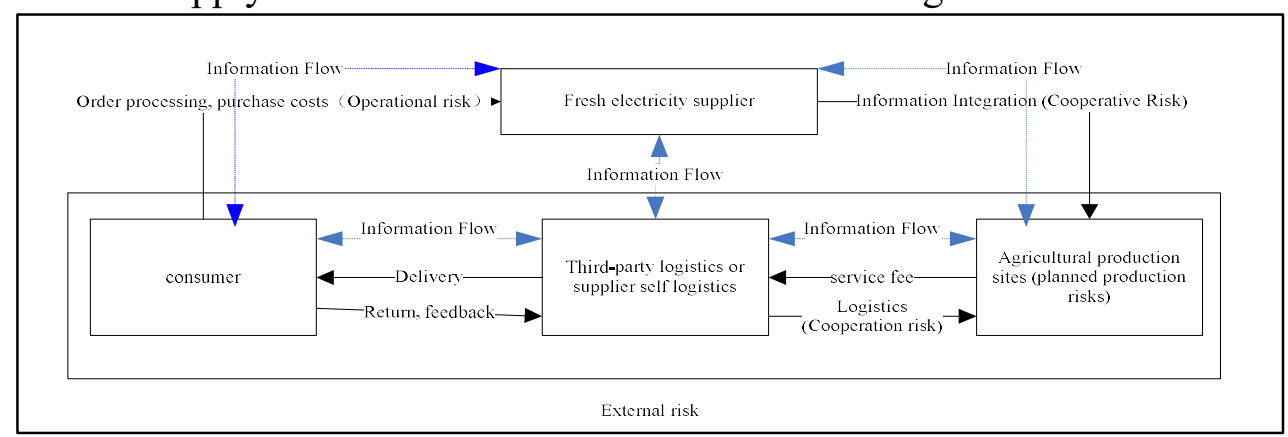

Figure 1. Risk Identification Diagram of Fresh Produce Supply Chain under O2O model

\subsubsection{External Environmental Risks Mainly Refer to.}

(a) The risk of natural disasters; fresh agricultural products are highly dependent on the natural environment. Uncertainty of the natural environment and frequent occurrence of natural disasters will affect the yield and quality of fresh produce.

(b) Political risks; The relevant policies, laws, and regulations of the fresh agricultural products and logistics industry promulgated by the government all have a significant impact on the development of fresh produce under the $\mathrm{O} 2 \mathrm{O}$ model. 
(c) Economic environment risk; the development of electronic commerce under the economic environment directly affects the overall supply chain operation of fresh agricultural products.

\subsubsection{Cooperative Risks Mainly Refer to.}

(a) Trust risk: Due to the characteristics of small production and large markets of fresh produce supply chain under $\mathrm{O} 2 \mathrm{O}$ model, the cooperation relationship between supply chain nodes is loose, there is no trust, members pay too much attention to their own interests, and the whole supply chain is random larger sex.

(b) E-commerce platform risk: The operation and development status of the online e-commerce platform in the $\mathrm{O} 2 \mathrm{O}$ model and different marketing strategies directly affect the online trading and offline purchasing power of fresh produce.

(c) User experience risk: The purchase process of fresh agricultural products under the $\mathrm{O} 2 \mathrm{O}$ model is virtual, and the satisfaction level of consumers when they experience consumption under the line of community convenience stores directly affects the probability of secondary purchases of consumers.

\subsubsection{Planned Production Risks Mainly Refer to.}

(a) Quality risk. The quality of fresh agricultural products is the value of the entire supply chain. Pesticide residues, residues of heavy metals, and deteriorating losses in circulation directly determine the degree of customer satisfaction and the return of supply chain funds [6].

(b) Inventory risk. The inventory risk is the losses caused by the improper inventory storage during the production of the original property and the storage of the warehouse,by increasing the production, planning, supply, inventory, and supply of the upstream suppliers in the supply chain. Market sales risk [7].

\subsubsection{Logistics Risks Mainly Refer to.}

(a) Transportation risks. Due to the specific requirements for all aspects of logistics during the transportation of fresh products. Unreasonable modes of transportation, poor packaging, and unbalanced transport conditions may all result in logistics risks.

(b) Distribution risk. Delivery requiring a lot of manpower and material resources and preservation equipment. The "last mile delivery" in the cold chain directly affects the degree of closed-loop convergence of the fresh supply chain under $\mathrm{O} 2 \mathrm{O}$.

(c) Cold chain technology risks. The cold chain logistics technology in our country is relatively backward, which increases the logistics cost and hinders the development of the entire supply chain [8].

(d) Cold chain infrastructure risk. The infrastructure such as cold storage, cold chain cars, quick-freezing cold storage and quick-freezing tunnel machines are not perfect, the distribution of cold storage is uneven, and the cold chain infrastructure is not able to meet the demand of cold chain logistics.

\subsubsection{Operational Risks Mainly Refer to.}

(a) Information asymmetry risk. Under the $\mathrm{O} 2 \mathrm{O}$ model, the larger the supply chain of agricultural products is the most complex the information structure, and the greater the risk of incompatibility between nodes. Because information caused by "bullwhip effect" expands and distorts in the process of transmission, information stagnation or leakage leads to information asymmetry risk.

(b) Uneven distribution of benefits. The different levels of culture in each node of the supply chain, its own management and information channels, and operating costs are different. The interests are unevenly distributed, which affects the stability of the overall supply chain operation.

\section{The Risk Assessment Based on Multistage Fuzzy Comprehensive Evaluation Method}

\subsection{The Basic Principle of Multistage Fuzzy Comprehensive Evaluation Method.}

This article mainly uses a fuzzy comprehensive evaluation method combined with the analytic hierarchy process. The method of fuzzy mathematics is adopted for the processing of quantitative analysis indexes [9], and the combination of expert survey and questionnaire survey is used for 
qualitative analysis indexes, so as to realize the perfect combination of quantitative analysis and qualitative analysis [10].

\subsection{An Example— the SF Optimal Company.}

SF Express is preferred to be built in 2012. It is a vertical fresh food e-commerce provider specializing in high-quality fresh produce and foods. Its basic operating model is a fresh shopping method that allows customers to place orders online and offline. Through the powerful logistics system of SF Express and the offline experience shop of SF Hacker, we will combine the "wind net + ground net + warehouse net + shop net" in all directions to jointly complete the optimization of fresh produce within 24 hours from the "branch" To tongue" shopping process.

\subsection{The SF-Optimized Supply Chain Risk Assessment.}

\subsubsection{Indicator Evaluation.}

The indicator system consists of five first-level indicators and 14 second-level indicators. Qualitative indicator evaluation is based on the related experience of relevant professionals in the O2O model fresh products in the logistics industry on the impact of each index on the SF-optimized supply chain. The AHP 1-9 fractional scale method was used to establish the relationship between the evaluation indicators. Combining qualitative indicators with quantitative indicators, the SF-optimized fuzzy comprehensive evaluation matrix for supply chain risk can be obtained, as shown in table 1.

Table. 1 First-level index judgment matrix

\begin{tabular}{cccccc}
\hline & $\begin{array}{c}\text { external environmental } \\
\text { risk }\end{array}$ & $\begin{array}{c}\text { cooperation } \\
\text { risk }\end{array}$ & $\begin{array}{c}\text { planning } \\
\text { production risk }\end{array}$ & $\begin{array}{c}\text { logistics } \\
\text { risk }\end{array}$ & $\begin{array}{c}\text { operational } \\
\text { risk }\end{array}$ \\
\hline external environmental & 1 & 3 & 5 & 5 & 3 \\
$\begin{array}{c}\text { risk } \\
\text { cooperation risk }\end{array}$ & $1 / 3$ & 1 & 3 & 1 & 9 \\
planning production & $1 / 5$ & $1 / 3$ & 1 & $1 / 3$ & 5 \\
risk & $1 / 5$ & 1 & 3 & 1 & 3 \\
\hline logistics risk & $1 / 3$ & &
\end{tabular}

\subsubsection{Determination of Weights of Indicators.}

Combining qualitative and quantitative indicators, the fuzzy comprehensive evaluation matrix of the risk factors of the preferred fresh agricultural product supply chain can be obtained: external environmental risk assessment matrix:

$$
\mathrm{Y}_{1}=\left[\begin{array}{ccccc}
0.1 & 0.2 & 0.4 & 0.2 & 0.1 \\
0 & 0.2 & 0.6 & 0.1 & 0.1 \\
0.2 & 0.2 & 0.5 & 0.1 & 0
\end{array}\right]
$$

Table 2 SF-Fuzzy Qualitative Index Fuzzy Evaluation Table

\begin{tabular}{|c|c|c|c|c|c|c|c|c|}
\hline $\begin{array}{l}\text { Target } \\
\text { layer }\end{array}$ & Main risk factor & & High:10 & Higher:8 & General:6 & Lower4 & Low:2 & Score: $D_{\mathrm{kn}}$ \\
\hline \multirow{14}{*}{ The risk } & \multirow{4}{*}{$\begin{array}{l}\text { External } \\
\text { environmental risk }\end{array}$} & $\begin{array}{c}\text { Natural disaster } \\
\text { risk }\end{array}$ & 0.1 & 0.2 & 0.4 & 0.2 & 0.1 & 6 \\
\hline & & Political risk & 0 & 0.2 & 0.6 & 0.1 & 0.1 & 6.8 \\
\hline & & Economic risk & 0.2 & 0.2 & 0.5 & 0.1 & 0 & 8 \\
\hline & & Trust risk & 0.2 & 0.2 & 0.3 & 0.2 & 0.1 & 7.4 \\
\hline & \multirow[t]{2}{*}{ Cooperation risk } & $\begin{array}{l}\text { E-commerce } \\
\text { platform risk }\end{array}$ & 0.5 & 0.2 & 0.2 & 0.1 & 0 & 9.2 \\
\hline & & $\begin{array}{l}\text { User experience } \\
\text { risk }\end{array}$ & 0.6 & 0.3 & 0.1 & 0 & 0 & 10 \\
\hline & Planning & Quality risk & 0.4 & 0.3 & 0.2 & 0.1 & 0 & 9 \\
\hline & \multirow{3}{*}{ Production risk } & Inventory risk & 0.3 & 0.2 & 0.2 & 0.2 & 0.1 & 7.8 \\
\hline & & Transportation risk & 0.6 & 0.3 & 0.1 & 0 & 0 & 10 \\
\hline & & Distribution risk & 0.6 & 0.2 & 0.2 & 0 & 0 & 9.8 \\
\hline & \multirow[t]{2}{*}{ Logistics risk } & $\begin{array}{l}\text { Cold chain } \\
\text { technology risk }\end{array}$ & 0.4 & 0.3 & 0.2 & 0.1 & 0 & 9 \\
\hline & & infrastructure risk & 0.3 & 0.3 & 0.2 & 0.1 & 0.1 & 8.2 \\
\hline & \multirow{2}{*}{ Operational risk } & $\begin{array}{l}\text { Information } \\
\text { asymmetry risk }\end{array}$ & 0.2 & 0.4 & 0.2 & 0.2 & 0 & 8.2 \\
\hline & & $\begin{array}{l}\text { benefit allocation } \\
\text { risk }\end{array}$ & 0.2 & 0.3 & 0.2 & 0.2 & 0.1 & 7.6 \\
\hline
\end{tabular}


According to formula:

$$
D_{k}=Y_{k} \cdot u^{\prime}=\left[\begin{array}{c}
D_{k 1} \\
D_{k 2} \\
\ldots \\
D_{k n}
\end{array}\right](k=1,2, \ldots, 5), D_{1}=\left[\begin{array}{c}
6 \\
6.8 \\
8
\end{array}\right]
$$

The same reasoning can be obtained as shown in table2.

From the above discussion, the weight of each index can be calculated. The relative importance of each secondary index in the first-level index can be obtained from the comprehensive evaluation scores of the risk factors and main factors of each secondary factor. Based on the analysis of the SF Express's supply chain evaluation system construction and survey questionnaires, we can see that the company's first-level risk assessment is: logistics risk $>$ cooperation risk $>$ planned production risk $>$ operational risk $>$ external environmental risk.as shown in table 3.

\subsubsection{Relative Weight of Secondary Risk Indicators.}

$$
\mathrm{H}_{\mathrm{ki}}=\mathrm{w}_{\mathrm{ki}} \cdot \mathrm{D}_{\mathrm{ki}}(\mathrm{k}=1,2, \cdots, 5), \quad(\mathrm{i}=1,2, \cdots, \mathrm{n})
$$

Natural disaster risk:

$$
H_{11}=\sqrt[n]{\left(w_{k i} \cdot D_{k i}\right) \cdot H_{k} / \sum_{k=1}^{n} H_{k}}=\sqrt[3]{(0.6509 .6) \cdot 6.5464 / 42.3056}
$$

From the above analysis, we can see that the top five risk indicators in the secondary indicators are: quality risk $>$ information asymmetry risk $>$ distribution risk $>$ e-commerce platform risk $>$ user

\begin{tabular}{|c|c|c|c|c|c|c|}
\hline $\begin{array}{l}\text { Target } \\
\text { layer }\end{array}$ & Main risk factor & $\begin{array}{l}\text { Secondary risk } \\
\text { factor }\end{array}$ & $\begin{array}{l}\text { Secondary risk } \\
\text { factor } \\
\text { weights: } w_{k i}\end{array}$ & $\begin{array}{l}\text { Comprehensive } \\
\text { assessment of } \\
\text { major factors: } H_{k}\end{array}$ & $\begin{array}{l}\text { Secondary } \\
\text { risk } \\
\text { proportion } \\
\text { evaluation } \\
\text { value }\end{array}$ & $\begin{array}{c}\text { Secondary } \\
\text { risk index } \\
\text { ranking }\end{array}$ \\
\hline \multirow{14}{*}{$\begin{array}{l}\text { The } \\
\text { risk }\end{array}$} & \multirow{3}{*}{$\begin{array}{c}\text { External } \\
\text { environmental } \\
\text { risk }\end{array}$} & $\begin{array}{c}\text { Natural disaster } \\
\text { risk }\end{array}$ & 0.651 & \multirow{3}{*}{6.5464} & 0.845 & 7 \\
\hline & & Political risk & 0.126 & & 0.511 & 14 \\
\hline & & Economic risk & 0.223 & & 0.650 & 13 \\
\hline & \multirow{3}{*}{$\begin{array}{l}\text { Cooperation } \\
\text { risk }\end{array}$} & trust risk & 0.096 & \multirow{3}{*}{9.3084} & 0.539 & 13 \\
\hline & & $\begin{array}{l}\text { E-commerce } \\
\text { platform risk }\end{array}$ & 0.552 & & 1.038 & 4 \\
\hline & & $\begin{array}{c}\text { User experience } \\
\text { risk }\end{array}$ & 0.352 & & 0.918 & 5 \\
\hline & \multirow{2}{*}{$\begin{array}{c}\text { Planning } \\
\text { production risk }\end{array}$} & Quality risk & 0.750 & \multirow{2}{*}{8.7} & 1.178 & 1 \\
\hline & & Inventory risk & 0.250 & & 0.633 & 10 \\
\hline & \multirow{4}{*}{ Logistics risk } & $\begin{array}{c}\text { Transportation } \\
\text { risk }\end{array}$ & 0.290 & \multirow{4}{*}{9.7008} & 0.903 & 6 \\
\hline & & $\begin{array}{c}\text { Distribution } \\
\text { risk }\end{array}$ & 0.569 & & 1.064 & 3 \\
\hline & & $\begin{array}{c}\text { Cold chain } \\
\text { technology risk }\end{array}$ & 0.085 & & 0.647 & 9 \\
\hline & & $\begin{array}{l}\text { Infrastructure } \\
\text { risk }\end{array}$ & 0.056 & & 0.569 & 12 \\
\hline & \multirow{2}{*}{$\begin{array}{l}\text { Operational } \\
\text { risk }\end{array}$} & $\begin{array}{c}\text { Information } \\
\text { asymmetry risk }\end{array}$ & 0.750 & \multirow{2}{*}{8.05} & 1.0818 & 2 \\
\hline & & $\begin{array}{c}\text { Benefit } \\
\text { allocation risk }\end{array}$ & 0.250 & & 0.601 & 11 \\
\hline
\end{tabular}
experience risk, specifically, the sub-risk ratio evaluation value and index ranking table 3 shows. Table. 3 Comprehensive Assessment of Major Factors and Secondary risk factor weights score table 


\section{Countermeasures}

\subsection{Strengthen the Quality Control of Fresh Produce.}

Strictly control the quality of product output and ensure the quality of fresh produce from the source. At present, SF prefers to adopt the direct sales model of origin, using SF Express's powerful courier transportation to achieve 24-hour speed from branch to tongue. The combination of farm direct sales and merchants entering the platform model can now be combined with invitational merchants to enter the platform model. This will facilitate the management and control of the sales quality of merchants to a certain extent, thus reducing the possibility of quality risks.

\subsection{Establishing an Information Sharing Platform.}

Improve the information communication and exchange mechanism, do a good job of market positioning and market environment analysis, closely integrate the pace of the platform with the development of the times, and reduce the occurrence of corporate supply chain risks. Establish a full trace ability system to achieve product transparency and avoid oversupply reduction caused by heavy production and light sales.

\subsection{Optimize the "Last Mile" Delivery.}

Expand the cooperation model of community convenience stores and community supermarkets, improve the coverage of "cold shipment" networks, implement the "last mile" distribution network shopping, send self-collection, and centralize delivery and contract delivery and other delivery methods to ensure the delivery of products. Timeliness and freshness. Build a city-wide distribution logistics system, improve the quality of distribution staff, enable employees to establish risk awareness in the distribution of fresh products, and effectively control distribution risks.

\subsection{O2O Brand Building.}

Use of e-commerce platform to implement data collection, accurate positioning of customer groups based on big data, implementation of precision marketing and integrated marketing combined with marketing strategies, so as to establish customer awareness of the brand, develop the characteristics of agricultural products economy. Use star product marketing methods to drive sales of other products.

\subsection{Increase User Experience Satisfaction.}

Conduct professional and modular training for offline experience shop employees, enhance the professionalism of fresh employees, and establish a sense of service that "customers are God". Train employees' overall awareness, enhance customer experience value, and increase customer satisfaction.

\section{Conclusion}

In a word, for the operators of fresh e-commerce supply chain node enterprises, the e-commerce development industry of fresh agricultural products in China has shown a vigorous development trend, and the risk of fresh agricultural product supply chain will always exist under the $\mathrm{O} 2 \mathrm{O}$ model, and the supply chain risks Identifying and analyzing the sources of risks can effectively prevent and reasonably avoid risks. The author believes that in the future $\mathrm{O} 2 \mathrm{O}$ model, fresh produce will inevitably make people's life easier and faster. Fresh produce under the $\mathrm{O} 2 \mathrm{O}$ model will also become an integral part of the Internet economy.

\section{Acknowledgements}

This work is supported by the Ministry of Education of Humanities and Social Sciences Youth Funded Projects (No. 14YJC630193). 


\section{References}

[1]. Zhang Dingy, Zhang Mengjia,et all, Study on the Willingness to Buy Fresh Agricultural Products under the O2O Model Based on the Perceptual Revenue-Perceived Risk Framework[J]. China Soft Science, 2015, 06:128-138.

[2]. Sun Cu. Design and Application of Trace ability System for Fresh Produce Supply Chain Based on NFC Technology [J]. Jilin University, 2016.

[3]. Sun Yang, Lu Sinew. Risk analysis of supply chain of fresh agricultural products electricity suppliers [J]. Anhui Agricultural Sciences, 2016, 22:229-232+238.

[4]. Cu Juan, Zhang Deben. Evaluation Model of Emergencies in Fresh Agricultural Supply Chains [J]. Statistics and Decisions, 2012, 12:41-43.

[5]. Huang Zeyu,Xu Xiaoping, Zhou Tao.The research on the Influencing factors of farmers, income in supply chain of agricultural super docking[J].Advance in Applied Economics and Finance,2012,1(04):207-209

[6]. Bu Hong. Information empowers vegetable supply chain: A study of information needs and sharing strategies among farmers and vendors, 2015(117):81-90.

[7]. Wang Dongguan, Li Hue. Research on Supply Chain Risk Identification and Processing [J]. Business Era, 2011, (04): 15-16.

[8]. Leapt, P., \& Revoredo, G. C. Risk and Resilience in Agri-food Supply Chains: The Case of the ASDA Pork Link Supply Chain in Scotland [J]. Supply Chain Management: An International Journal, 2013, 18(2): 219-231.

[9]. Hu Shubuta, Jibe Jialing, ET all. Research on Competitiveness of National High-tech Zone Based on Multi-level Fuzzy Comprehensive Evaluation Method [J]. Soft Science, 2011, 05:53-56.

[10]. Chang Nana. Performance Evaluation of Supply Chain Management Based on Multi-level Fuzzy Comprehensive Evaluation Method [J]. Modern Business Industry, 2010, (23):58-59. 